\title{
DO MITO AO EXPERIMENTO: A CARTOGRAFIA E A URBANIZAÇÃO DE GOIÁS
}

\author{
NO SÉCULO XVIII \\ FROM MYTH TO EXPERIMENT: THE CARTOGRAPHY AND THE URBANIZATION OF GOIÁS DURING \\ THE XVIII CENTURY \\ Deusa Maria Rodrigues Boaventura* \\ dmrbester@gmail.com
}

\begin{abstract}
RESUMO: A urbanização de Goiás no século XVIII se realizou segundo uma estratégia de posse e controle das terras coloniais, elaborada por Portugal. Para o interior do Brasil essas ações convivem com a mítica ideia da presença do ouro na região e podem ser vistas a partir do período filipino, com o governador D. Francisco de Souza, quando se deu a formação de incursões e elaboração de mapas. Mas só nos fins do Seiscentos, houve uma maior supervisão desse sertão, com medidas que redefiniram um programa de ocupação. Nesse momento Portugal já se encontrava com um corpo de escolas que formavam engenheiros militares, prontos para a realização de tarefas que iam desde os levantamentos cartográficos até a fundação de cidades. Em Goiás, essas novas orientações são vistas no início do século XVIII, após as notícias do rico metal. Contribuíram para a definição dos limites territoriais da capitania, com a formação de núcleos urbanos, com a instalação da capital Vila Boa, da Prelazia, e dos mapas feitos por sertanistas e engenheiros militares.
\end{abstract}

PALAVRAS-ChAVE: Urbanização e controle, Cartografia, Capitania de Goiás.

ABSTRACT: The urbanization process of Goiás during the XVIII century was planed within a strategy of ownership and control of the colonial land, carried on by Portugal. Towards Brazil's midlands, these actions interact with the mythic idea of the presence of gold on these territories and can be seen since the Felipe's period, with the governor D. Francisco de Souza, when incursions where planed and maps were elaborated. But only at the end the XVII century was happening a better supervision of this backcountry, with measures that would redefine an occupation program. At that time, the Portuguese crown already had an educational administration forming military engineers, ready to execute tasks from land survey to founding cities. In Goiás, these new orientations were seen at the beginning of the XVIII century, after the report of the wealthy metal. They contributed to the definition of the captainship's territory limits, forming urban nucleus, setting up the capital Vila Boa, Prelacy and maps that had been drafted by backcountry men and military engineers.

KEYWORDS: Urbanization and control, Cartography, Captainship of Goiás.

\section{Introdução}

A urbanização da Capitania de Goiás no século XVIII esteve ligada a uma ação colonizadora da metrópole portuguesa que se orientava por uma antiga estratégia de posse e controle do território. Essa política partia do pressuposto de que o estabelecimento de

\footnotetext{
*Doutora pela FAU-USP e professora de Teoria e História da arquitetura e urbanismo, nos cursos de graduação da PUC- Goiás e UEG. Atua também como docente no Programa de Graduação em História da PUC-GO.
} 
núcleos urbanos garantiria a efetiva ocupação de espaços de "soberania ainda não definida". No Brasil, essa forma política de gestão do território encontrou suas balizas iniciais mais precisamente com a instituição do governo geral, em 1594. Nessa época, a presença do controle metropolitano na formação dos primeiros núcleos urbanos foi marcada pela ação dos donatários. Uma participação mais direta do Estado só aconteceu após as três primeiras décadas dessa centúria, com a fundação de cidades, como Salvador (1549), Rio de Janeiro (1565) e Filipéia de Nossa Senhora das Neves (João Pessoa, 1585). Foi nesse momento que Portugal passou a contar, além da legislação sesmarial, com outros instrumentos de controle do território para proteger as posses portuguesas, como as últimas inovações científicas da cartografia e os eficazes sistemas de fortificação.

No período filipino (1580-1640) este controle também ocorreu com o levantamento de várias fortalezas, particularmente nas regiões entre a Bahia e São Luís do Maranhão e entre Santos e Rio de Janeiro. Para tanto, contou-se com a ação dos engenheiros militares Batista de Antonelli, Luís Frias de Mesquita e do italiano Baccio de Filiccaia (1597-1602). No centro da colônia, essa política efetivou-se por intermédio do governador-geral e superintendente das minas do Brasil D. Francisco Souza. Para colocá-la em prática, ele contou com a colaboração dos engenheiros Geraldo Beting e do citado Baccio de Filiccaia.

Decorridos esses anos de reinado dos Filipes e após as guerras da Restauração, o Brasil passou a ser a principal colônia de Portugal tanto em termos territoriais quanto econômicos. Os conflitos decorrentes dessa recuperação lusa dinamizaram o início do intrincado processo de definição das fronteiras americanas entre as duas nações ibéricas. Por motivos tão expressivos como esses, a Coroa portuguesa delineou uma estratégia que objetivava o controle direto do território colonial por intermédio de reformas em suas estruturas administrativas, como a instalação, em 1643, do Conselho Ultramarino e a gradativa transferência do controle das capitanias hereditárias para a metrópole. Além dessas alterações, foram enviadas da metrópole corporações de funcionários do reino, formadas por oficiais da justiça e da fazenda, servidores do clero secular e, mais notadamente, por vários engenheiros militares, tidos como os maiores responsáveis pela construção de sistemas de fortificação e urbanização colonial. Naquele momento, a criação de vilas e cidades, elementos essenciais para a soberania territorial, passava a ser 
prerrogativa exclusiva do Estado, assegurada pelas Cartas Régias aos governadores (ROSSA, 1995).

Até então, como referido anteriormente, a urbanização do território brasileiro desenvolvia-se praticamente na região litorânea, exceto alguns pequenos povoados indígenas distantes da costa, que logo se transformaram em pontos estratégicos para algumas incursões ao interior da colônia em busca de índios e das fantásticas riquezas celebradas pelo antigo mito do Eldorado. Mas, apesar de tais esforços, somente no fim do Seiscentos os tesouros auríferos foram descobertos, demonstrando o grande potencial da região e a necessidade imediata de ações governamentais para garantir o controle supervisionado do precioso sertão.

Mas foi, portanto, mais precisamente a partir de 1717 que quase todos os núcleos urbanos criados no sertão passaram a obedecer a uma forma de planejamento (DELSON, 1997). Regulamentos para as regiões das minas, elaboração de uma jurisdição que incidisse sobre os exploradores aventureiros, contenção das ampliações das primeiras terras justificadas pelas posses, expansão do território colonial a oeste de Tordesilhas, levantamentos cartográficos e combinação de um sistema de partilha de terras ou de direitos sobre ela, com o estabelecimento de povoações articuladas entre si, foram os fundamentos dessa nova política de ocupação organizada, particularmente, por engenheiros militares que utilizavam mapas, descrições e relatos corográficos para o conhecimento, a demarcação e a legitimação de territórios mais avançados.

Para a região de Goiás, não obstante a elaboração de alguns mapas no final do século XVII, esse foi o contexto que marcou o início de um melhor conhecimento e controle de seu território. Com a notícia do ouro, a Coroa buscou assegurar seu domínio econômico e territorial sobre estas terras, mediante uma série de procedimentos jurídico-administrativos, iniciados pela instalação de intendências e, posteriormente, pela criação da capitania e de sua capital, além de casas de fundição, caminhos reais e registros, dentre várias outras ações. A ideia de que a região teria sido conquistada apenas por aventureiros exploradores que fundaram arraiais livres de qualquer olhar de Portugal deve ser tomada com bastante cautela, uma vez que, mesmo ante as condições adversas da primeira entrada de 1722, já havia sido providenciado um Regimento datado de 30 de junho desse mesmo ano para 
descobrir minas de ouro e pedras preciosas no sertão (AHSP. Doc. In: Documentos Interessantes).

Após as providências estabelecidas previamente nesse Regimento, em 1726, sob orientação real, Bartolomeu Bueno da Silva retornou ao sertão dos Goyazes como seu superintendente. Acompanhado de dois engenheiros de minas, chegou para manter a ordem e o arcabouço tributário dos recém-descobertos veios auríferos. Mas, paralelamente ao início de sua gestão e com o intuito de marcar deliberadamente sua presença, a Coroa criou imediatamente a primeira paróquia no Arraial de Santana, em 1726, principiando, assim, a implantação das estruturas administrativas eclesiásticas. Mas, aproximadamente dez anos depois, Bueno foi afastado de seu cargo. Nessa mesma época (1736), no governo do Conde de Sarzedas e por questões de manutenção de poder e maior controle da região, a Corte determinou que as minas dos Goyazes fossem desmembradas do território de São Paulo e, na sequência, fundada a sua capital, Vila Boa de Goiás. Essa determinação, no entanto, só seria cumprida após o falecimento de Sarzedas, em 1739, quando D. Luís de Mascarenhas assumiu o governo. Ele demarcou as terras da capital próximas ao Arraial de Santana, localizado a oeste de Tordesilhas, em região de soberania não definida, justificada, posteriormente, pelo antigo direito romano expresso na expressão latina uti possidetis ita possideatis, que pode ser entendida por "se já possuis, continuai possuindo" (GUERREIRO, 1999, p. 28).

Paralelamente a esse conjunto de ações e para além das dificuldades inerentes à consolidação de uma estrutura organizacional em terras tão extensas e inóspitas, os sistemas administrativos foram fixando-se representados pelos governadores goianos, funcionários de El-Rey. Daí em diante, boa parte das novas expedições mineratórias deveriam ser promovidas por esses agentes políticos que passaram a responsabilizar-se pelo processo de construção do território. No fim da primeira metade do século XVIII, Goiás possuía uma vila, mais de 50 arraiais e 4 aldeamentos erguidos às margens da estrada de São Paulo, além de significativos levantamentos topográficos e cartográficos, feitos por determinação dos governadores e executados por auxiliares, como o engenheiro militar Francesco Tosi Colombina. 


\section{Os engenheiros militares e suas contribuições para a formação de territórios coloniais.}

Na colônia luso-brasileira, o trabalho dos engenheiros militares cartógrafos foi imprescindível, pois sempre que solicitados se destacavam por suas capacidades de exercerem tarefas tais como a urbanização de terras incultas. Em terras goianas, por exemplo, na primeira metade do século XVIII, eles se evidenciam pelos vários levantamentos topográficos que buscavam responder à nova política de urbanização e organização territorial. Mas não só nessas tarefas os engenheiros estavam diretamente envolvidos, mas também nas atividades da administração do governo e em outras mais técnicas, como a elaboração de desenhos de mapas, fortificações e malhas urbanas. Essa múltipla capacidade de atuação, no entanto, não teve início no Setecentos, derivou-se da anterior necessidade de ocupação e defesa dos domínios portugueses do século XVI, que obrigou Portugal até mesmo a superar seu atraso científico em relação às demais nações europeias.

Nessa época, procurando resolver essa condição de retardamento, a Coroa tomou duas atitudes: receber italianos para atualizar os profissionais portugueses e encaminhar técnicos locais, como João de Castilho, Antônio Rodrigues e Francisco de Holanda, para se especializarem na Itália. O resultado dessa iniciativa permitiu a Portugal o conhecimento de técnicas e sistemas defensivos de fortificações ligados a novos conceitos teóricos do urbanismo, que pregavam a representação de um mundo recente, com cidades que expressavam relações socioculturais diferentes, nas quais o homem era racionalmente o centro do cosmos. Foi por intermédio do esforço de superação desse atraso científico que, a partir do reinado de D. João III, essas novas concepções urbanísticas chegaram ao território luso e, depois, alcançaram suas terras conquistadas, onde havia uma grande exigência por controle e ocupação.

No entanto, esses novos conceitos de cidade só se consolidaram por volta da segunda metade do século XVI quando se articularam com a forma de ensino português, que visava associar a Tratadística Clássica com as acumuladas e diversificadas práticas urbanísticas. Em 1562, o resultado desse empenho permitiu a institucionalização da Aula do Paço, cujas contribuições ajudaram no aperfeiçoamento dos mapas cartográficos (D'AGOSTINO, 2004, p. 290). 
Igualmente denominada Escola Particular de Moços Fidalgos ou Lição dos Moços Fidalgos, esta instituição de ensino técnico foi uma das tentativas de resposta aos problemas científicos de Portugal. Organizada em 1562 por Dona Catarina, era voltada à educação de D. Sebastião e dos jovens nobres destinados à carreira das armas e das empresas marítimas. Um dos maiores orientadores da Aula do Paço foi Pedro Nunes (? - 1578), cosmógrafo-mor, cartógrafo e matemático que, entre 1536 e 1541, ministrava lições particulares a um grupo bastante restrito com conteúdos que "[...] conjugavam o estudo das obras clássicas (a 'Esfera' de Sacrobosco, a 'Geografia' de Ptolomeu, a 'Física' de Aristóteles) com uma componente prática exercitada, por exemplo, em observações astronômicas" (CONCEIÇÃO, 2000, p. 29).

Outro grande personagem dessa escola foi Antônio Rodrigues, engenheiro militar e arquiteto, responsável pela cátedra de arquitetura entre 1572 e 1577 . Merecedor de grande apreço, esse mestre escreveu o primeiro tratado português de arquitetura em 1576. Obra síntese da associação da Tratadística Italiana e da matemática portuguesa traz significativas especulações teóricas e ideológicas acerca do urbanismo quinhentista. Além desses dois mestres, cabe destacar que, no período filipino, outro cosmógrafo-mor, João Baptista Lavanha, substituiu Pedro Nunes dando continuidade aos trabalhos científicos da Aula do Paço.

No fim do Seiscentos, em Portugal, a carência de um número maior de técnicos em fortificação foi decisiva para a criação da Aula da Esfera (1580), orientada para o ensino de matemática, cosmografia (Esfera), geografia, hidrografia, astronomia, astrologia, náutica e, mais tarde, por expressa ordem régia, para a arquitetura militar. Tal escola, que se alongou até o início do século XVIII, era formada por professores de diferentes origens e, a partir da década de 30 do século XVII realizou mudanças nas referências teóricas "em matéria defensiva", passando da Tratadística Clássica, de matriz italiana, para as escolas flamengas e francesas (STAFFORDE, Ignácio, apud CONCEIÇÃO, 2000, p. 30). Entre seus ex-alunos de excelência, merecem menção aqueles que trabalharam ativamente no reino e em suas conquistas, como: os engenheiros Baccio di Filiccaia e Bartolomeu Zanit, o cosmógrafo João Teixeira Albernaz, o arquiteto João Nunes Tinoco e o importante tratadista Luís Serrão Pimentel. 
Por volta de 1594, foi instituída por Filipe II a Aula de Riscar, na mesma ocasião em que à experiência prática dos construtores militares e urbanizadores da Corte portuguesa somavam-se as ricas experiências de cosmógrafos e navegadores e dos trabalhos de Luís Dias no Brasil. Sediada no Paço da Ribeira, recuperava as lições de matemática de Pedro Nunes e os estudos da Tratadística Italiana. Seus aprendizes assistiam ao curso do mestre de obras real Filipe Terzio, nomeado em 1590, e o complementavam com as aulas teóricas de João Batista Lavanha.

Grosso modo, em quase todas essas escolas a base do ensino era a geometria, a matemática, a cosmografia e a cartografia. Juntas, essas ciências apresentavam um conhecimento à base de rigorosos cálculos fundamentais tanto para a náutica como para os levantamentos territoriais, e que, em terra ou mar, eram instrumentos de dominação (D'AGOSTINO, 2004).

No contexto da Restauração e com a pressão dos novos acontecimentos, a premente necessidade de defender as cidades portuguesas e o inexorável início do processo de demarcação das fronteiras da colônia, dezenas de técnicos estrangeiros foram convidados a trabalhar em Portugal. Ao introduzirem novos paradigmas, esses técnicos contribuíram para a fundação da primeira escola portuguesa especializada em fortificação. Denominada Aula de Fortificação e Arquitetura Militar (1647), esta escola tornou-se o espaço de confluência das antigas tradições da ciência náutica e dos novos domínios da matemática.

Dessas aulas, resultaram os importantes textos de Luís Serrão Pimentel, e como nos tratados de Pedro Nunes, a questão do pragmatismo e da experiência reaparece nesses trabalhos como eixo central. Isso sinaliza a importância da transferência do conhecimento prático para uma execução fácil e adequada aos rígidos princípios gerais e à flexibilidade das regras particulares, tanto na fundação de novas cidades como na intervenção de malhas urbanas consolidadas.

Esse foi o princípio de legitimação do pragmatismo dos arruadores no Brasil, o que constituiu, em síntese, "[...] a validação acadêmica de uma linha de trabalho já experimentada e o assentamento das bases para uma continuidade da escola portuguesa" (CONCEIÇÃO, 2000, p. 37). Mas o pragmatismo sustentado por Serrão, adverte Araújo 
(1998), não correspondeu ao empirismo, nem mesmo a um descaso com os postulados geométricos da criação urbana clássica.

A eficácia dos trabalhos dos urbanizadores se resumia, então, às suas boas formações, guiadas pela ideia de flexibilidade e adaptabilidade às circunstâncias locais, e as influências também dos tratados franceses de Antoine De Ville, de 1628, e do Conde de Pagan, de 1640, mais voltados para as práticas defensivas das cidades existentes. $\mathrm{Na}$ segunda metade do século XVII, em razão da política de expansão e delimitação do território francês, esse sistema adquiriu corpo teórico e notabilizou o engenheiro Le Preste Vauban pelas cidades que havia fortificado (TEIXEIRA; VALLA, 1999).

Nas terras conquistadas no século XVIII, esse modo de "fazer cidade" não foi propriamente uma simples continuidade dos procedimentos do Seiscentos. Constituiu, em vez disso, a base para a consolidação de um método teórico-prático que ganhou plena luz nas reformulações de Manuel de Azevedo Fortes, as quais visavam ao ensino dos engenheiros militares. Seu tratado O Engenheiro Português: Dividido em dous Tratados, sob forte influência da doutrina racionalista de Descartes, caracteriza-se pela lógica de sua estrutura e transparência de seus conceitos (MOREIRA E ARAÚJO, 2000).

O texto de Azevedo Fortes apresenta seções que exprimem a ruptura da arquitetura civil com a engenharia militar, opondo-se à velha tradição do discurso português que unia as duas áreas de conhecimento. A engenharia deveria ser uma ciência independente e com regras preestabelecidas, contando ainda com a criação de um corpo técnico altamente qualificado, acompanhado por medidores auxiliares. Sob essas novas condições, os engenheiros passariam, com o decorrer do tempo, a exercer funções de caráter mais civilizatório, executando obras destinadas a servir e melhorar as condições de vida da população, como cais, diques, faróis, pontes, calçadas, aquedutos, etc.

Em síntese, essas ações representavam o próprio ordenamento do território. Era um trabalho duro de levantamento e de marcação de divisas que permitia construir e conhecer os territórios portugueses e brasileiros. Para tantas competências e demandas de trabalho, o engenheiro-mor Azevedo Fortes havia escrito em 1722, entre outros textos, o Tratado do modo o mais fácil e o mais exacto de fazer as cartas geográficas. Na colônia setecentista, esse tratado e as contribuições das antigas Aulas Régias de Salvador; da Aula das Fortificações e Arquitetura de 1698, no Rio de Janeiro, da Aula do Maranhão, de 1699; 
de Recife, de 1701 e ainda das inúmeras experiências de levantamentos e demarcações territoriais subsidiaram o modo de fazer as cidades dessa época, marcando o processo de construção e urbanização de Goiás por meio de controles cartográficos.

Na região da Capitania de Goiás, os primeiros indícios de um controle territorial por meio de levantamentos cartográficos retrocedem ao remoto período dos Felipes (15801640), com o governador-geral Dom Francisco Souza e seu auxiliar, o engenheiro-mor do Brasil, Baccio di Filiccaia (1597-1602), os quais incitavam a formação de expedições à região do Eldorado. Essas foram algumas das incursões movidas pelo mito e pela razão, as quais adquiriram as primeiras informações, que, embora escassas, estão refletidas nos mapas do Brasil de 1665, 1670 e 1675, indicando o conhecimento possível do território naquela época, porém necessário ao preparo de expedições para a exploração de minas e sua futura posse.

O autor de um dos principais mapas cartográficos foi o cosmógrafo João Teixeira Albernaz II, contemporâneo de Luís Serrão Pimentel (1613-1679) e de Baccio di Filiccaia. Foi ele o último da família do quinhentista Luís Teixeira e, portanto, o herdeiro de antigos conhecimentos náuticos e das inovações cartográficas introduzidas em Portugal pela França, Países Baixos e Alemanha. Por essa razão, certamente João Teixeira conhecia o velho Roteiro-Atlas (1574) do avô Luís Teixeira e utilizou-o para o enriquecimento da cartografia corrente, notadamente aquelas de 1642, 1665, 1670 e 1675 (CORTESÃO, 1965), nas quais se encontram os cursos dos rios Tocantins e Paraguai e, pela primeira vez, a figuração da ilha do Bananal (Paraupava) no rio Araguaia.

Não obstante essas preciosas cartas elaboradas por João Teixeira, a região do território goiano só foi plenamente conhecida no curso da primeira metade do século seguinte, no governo de D. João $V$, a partir da certeza da existência de ouro em seu interior. Foi exatamente esse metal um dos importantes fatores que impulsionaram a Coroa portuguesa a incentivar a formação de inúmeras incursões de exploração em direção a esta região e a aplicar uma política de ocupação que visava, com a fundação de povoados a oeste de Tordesilhas, antecipar o seu domínio territorial. 


\section{A cartografia e a construção do território de Goiás.}

A expansão e posse de Portugal nas terras além Tordesilhas há muito tempo vinham provocando profundos desentendimentos com a sua oponente, a Coroa espanhola, e gerando inúmeros conflitos entre ambas, porém intercalados por alguns momentos de trégua. Nos últimos anos do reinado de D. João V (1706-1750), houve um desses relativos tempos de paz entre as cortes, o que permitiu a Alexandre de Gusmão, o sagaz secretário do monarca, sugerir as bases para a efetiva demarcação dos limites do Brasil. Segundo uma política expansionista que remonta a pelo menos 1736 , este auxiliar da Coroa portuguesa elaborou um plano secreto de exploração dos territórios que ultrapassavam os limites estabelecidos pelo Tratado de Tordesilhas, incluindo o oeste da futura Capitania de Goiás. “O plano nasceu por proposta do Conselho Ultramarino e visava à realização do Novo Atlas do Brasil" (GUERREIRO, 1999, p. 25), peça chave para justificar a posse efetiva e a unidade do território, concretizando, posteriormente, os termos do importante Tratado de Madri, de 1750. A primeira metade do século XVIII colocou a região de Goiás sob esse desígnio, efetivado mediante levantamentos topográficos e a continuidade de várias outras expedições de reconhecimento, que permitiram a identificação de suas balizas naturais e a execução de mapas mais precisos que ajudaram na construção e ocupação do território.

No interior da colônia, os movimentos iniciais desse plano, coordenado pelos interesses geopolíticos e diplomáticos, podem ser observados nas descobertas auríferas (1718) (FERREIRA, 2000) de Pascoal Moreira Cabral nas adjacências dos rios Coxipó e Cuiabá; nas ordens do Conselho Ultramarino, de 1719, para que o engenheiro da Capitania de São Paulo averiguasse os possíveis avanços dos espanhóis e fizesse um mapa indicando os rios e cordilheiras que pudessem servir de divisas entre as partes dos domínios das duas coroas (FERREIRA, 2000) e na expedição de Bartolomeu Bueno, o filho, a Goiás no ano de 1722.

Entretanto, apesar de todas estas iniciativas, essas primeiras experiências de penetração pelo interior do Brasil foram realizadas por homens de reduzidos conhecimentos científicos, o que mostrou à metrópole as reais dificuldades de um trabalho cartográfico dessas proporções. Para o cumprimento dessa tarefa, seria imperativa a transferência dos últimos conhecimentos científicos para a metrópole e, posteriormente, para a colônia, tendo em vista a sua ocupação e urbanização. Tais motivos levaram Portugal à aquisição de relógios marcadores de longitude, de novas cartas de longitudes já observadas e à 
contratação de matemáticos europeus para a elaboração de novos mapas, dentre os quais Jean Baptiste Bourguignon d'Anville (1697-1782). ${ }^{1}$ No ano de 1722, em decorrência dessa necessidade, chegaram a Lisboa os jesuítas italianos João Baptista Carbone e Domingos Capacci, peritos nas matemáticas e na arte da arquitetura militar, que, com o engenheiro Manuel Azevedo Fortes, se destacavam pelas grandes inovações e contribuições ao processo de elaboração de mapas e pelo prenúncio, na obra deste último, da crítica iluminista (FERREIRA, 2001). Com eles, surgiram trabalhos de caráter mais científico, como a moderna cartografia lusa, que passou a contar com os cálculos das longitudes, e o urbanismo português, que se organizaria com maior regularidade. Esse conhecimento foi aplicado posteriormente às várias experiências brasileiras, alcançando, evidentemente, Goiás.

Para a concretização desse propósito, em 1729 Domingos Capacci empreendeu viagem ao Brasil acompanhado por outro jesuíta, o lisboeta Padre Diogo Soares, para ajudar no trabalho de levantamento e reconhecimento do território colonial. Em um alvará de 18 de novembro desse mesmo ano, D. João $V$ comunicou ao Vice-rei, aos governadores de todas as capitanias do Estado do Brasil e até às últimas freguesias dos sertões a nomeação desses dois padres, matemáticos e geógrafos da Companhia de Jesus, para a elaboração de "[...] cartas geográficas do Estado, tanto as do mar quanto as dos sertões" (CORTESÃO, 2001, Doc. 1729).

Os religiosos a serviço do plano secreto da política expansionista portuguesa representaram na colônia a passagem de uma "cultura de latitude e superfície", baseada na ciência e na prática marítima, para uma "cultura de longitude e profundidade" (CORTESÃO, 2001, p. 318) de fixação e topografia de expansão terrestre. A plena e eficaz realização do referido plano de exploração e ocupação das regiões de "soberania portuguesa não definida", assim como o próprio sucesso do Tratado de Limites, dependeu, em certa medida, desses cientistas matemáticos e dos diversos engenheiros militares. Os problemas de controle e exploração econômica dessas áreas só poderiam ser resolvidos com observações astronômicas ou uso de cronômetros que atingissem a perfeição e segurança necessárias

\footnotetext{
${ }^{1}$ D'Anville é "[...] aquele que, durante o século XVIII, verdadeiramente caracteriza, completa e simbolicamente a escola francesa de cartografia. Geográfico, historiador e cartógrafo, nomeado, após a morte de Delisle, Primeiro - Geógrafo do Rei, membro da Academia das Ciências e da Academia das Inscrições" (CORTESÃO, 1965 , p. 106).
} 
(CORTESÃO, 2001). Tudo seria materializado no Novo Atlas para o Brasil, que visava apresentar uma cartografia de acordo com métodos científicos (GUERREIRO, 1999).

A execução de mapas geográficos e cadastrais com o objetivo de reconhecer espaços incultos e suas potencialidades atestava as providências para o ordenamento do território. A tarefa, apesar de ser árdua, com sistemáticos trabalhos de levantamentos medições e marcação de divisas, significava controle e poder. A presença dos sacerdotes matemáticos em Goiás e a introdução dessas inovações representaram, assim, a confirmação de uma posse territorial ligada a uma acepção central da Coroa, que previa, além de seu controle, o estabelecimento e a organização de seus núcleos urbanos.

Assim sendo, a plena realização desse propósito exigiu dos matemáticos cartógrafos a elaboração de vinte mapas de diferentes pontos do Brasil: costa litorânea, desde a Capitania do Rio de Janeiro até o rio da Prata e a Colônia de Sacramento; interior do território de Goiás, desde $11^{\circ}$ de latitude Norte; Capitanias de Minas Gerais e São Paulo e uma grande região que também se estendia para o sul até o rio da Prata. Tal empreendimento enquadrava-se numa política de ocupação que já se desenvolvia desde o princípio do Setecentos com a elaboração de projetos para novas bases de controle de regiões em expansão.

Um material cartográfico de relevância para Goiás e, obviamente, para toda aquela região em expansão foi a Nova e primeira carta da terra firme, e costa do Brazil, ao Meridiano do Rio de Janeiro, desde o Ryo da Prata athé Cabo Frio, com o novo caminho do certão do Rio Grande athé a cidade de São Paulo (CORTESÃO 2001). Executada pelo Padre Diogo Soares, por volta de 1738 a 1740, foi dedicada e oferecida ao monarca D. João V.

Paralelamente a essas cartas, Capacci e Diogo Soares prepararam uma lista de latitudes (altura dos graus), calculadas somente com base na longitude de Vila Boa de Goiás. Esse trabalho, assim como outros que também se destinavam às demarcações, restringiu-se apenas ao circuito real. De padrão oficial e científico, fez parte de uma política secreta de omissão de dados concretos sobre as longitudes e as reais posições dos territórios, não só para os espanhóis como também para os portugueses e colonos. Essa política corroborou o desenvolvimento de uma cartografia de expressiva circulação local, empírica e espontânea, ao sabor dos sertanistas, mas que apresentava significativos equívocos. 
Somente no rico conjunto de mapas dos irmãos da Companhia de Jesus se encontravam informações mais corretas sobre a situação real dos confins além-mar, como: o mapa jesuítico editado em alemão por Mateus Seutter; a Carte du Cour du Maragnon ou de la Grande Riviere des Amazones, de Charles Marie de La Condamine (1745); a Descripçam do Continente da America Meridional que nos pertence com os Rios, e Montes, que os Certanejos mais experimentados, dizem ter encontrado, de Gomes Freire de Andrade (1746) e o Mapa de la Província y Missiones de la Compañia de IHS del Nuevo Reyno de Granada, do Padre José Gumilla (1741). Este mapa e os "riscos" de Gonçalves Pereira, as informações missioneiras e, por fim, as memórias e as viagens de sertanistas permitiram a execução do Mapa das Cortes. Este foi um instrumento essencial e engenhosamente construído com desvios estratégicos de informações favoráveis a Portugal, feito para que a Espanha aceitasse quase toda a proposta lusa de delimitação e legitimação do território invadido a oeste de Tordesilhas, como previa o Plano de Gusmão, iniciado em 1736. Essa manipulação nos mostra como os portugueses desenharam mentalmente e materialmente o território, antecipando assim uma posse que só se realizou com as negociações do Tratado de Madri, assinado em 14 de janeiro de 1750 (SIQUEIRA BUENO, 2001).

Nessa época, Goiás já contava com a capital Vila Boa, os aldeamentos de Rio das Pedras, Rio das Velhas, Santana e Lanhoso, no Desemboque e, os seus vários arraiais. Foram esses núcleos urbanos que, funcionando como suportes para a busca do ouro, contribuíram para a efetiva conquista dessas terras.

Mas, para a posse real da região, não bastavam apenas as informações sobre as longitudes de Vila Boa. O mapa intitulado Descripçam do Continente da América Meridional que nos pertence [...], apesar de possuir menor precisão, apresenta algumas indicações que ajudam no entendimento da formação do território de Goiás. De autoria desconhecida, mas atribuída a um militar do Rio de Janeiro, ele é datado de 5 de dezembro de 1746 e possui relativo rigor científico.

No texto Uma ideia de Brasil num Mapa inédito de 1746, Ferreira (2000), afirma que este mapa anônimo de 1746 é, indiscutivelmente, fruto das orientações de Gomes Freire de Andrade e que as informações foram levantadas para Alexandre de Gusmão. O historiador fundamenta sua posição em uma carta do engenheiro Francesco Tosi Colombina, de maio de 1747, na qual este afirma ter Gomes Freire de Andrade mandado fazer mapas para enviar 
informações à corte (FERREIRA, 2000). É verossímil, portanto, a consonância dessa carta com os propósitos do secretário do rei, cujo maior objetivo, era documentar, da melhor maneira possível, todo o território da colônia.

Fazer o melhor mapa possível deve ter sido a intenção desse autor desconhecido, que parece ter iniciado seu trabalho com os dados previamente existentes e espalhados por diferentes lugares tais como os relatórios de exploradores, os mapas de sertanistas e bandeirantes e os relatos de ouvidores, em especial o de Mato Grosso, e a Carte de la Terre Ferme du Perou, du Bresil et du Pays des Amazones, de Guillaume Delisle. Por essa razão, é razoável supor que o mapa denota o conhecimento do cartógrafo sobre a viagem de Antônio Pinheiro de Faria às missões espanholas dos Chiquitos, em 1740; a abertura da estrada de São Paulo até Goiás, por Bartolomeu Bueno da Silva, o filho, e sobre o caminho terrestre de Cuiabá para Goiás, executado em 1736 por Antônio Pinho de Azevedo, já que todas essas indicações se encontram registradas na tal Descripçam (FERREIRA, 2000).

Ferreira (2005) destaca também que, mesmo ciente das imprecisões das fontes, esse cartógrafo se preocupou com a representação das terras do interior do Brasil e com a interessante articulação das regiões de mineração com as litorâneas, ilustrada pelas representações dos caminhos anteriormente citados. De acordo ainda com este historiador, no mapa estão também refletidas as iniciativas de exploração das terras de soberania não definida, como os contatos estabelecidos pelos portugueses nas décadas de 1730 e 1740 com as Missões espanholas de Moxos e Chiquitos e a viagem do expedicionário Amaro Leite Moreira, que saiu de Goiás em 1739 em busca de ouro no sertão dos Araés.

Com base nessas indicações, pode-se suspeitar que outras expedições contemporâneas à de Amaro Leite Moreira estivessem associadas às mesmas iniciativas de reconhecimento geográfico e econômico do território goiano, o qual não se sabia ainda exatamente a quem pertencia. A primeira delas foi a que se fez pelo Tocantins até o Pará em 2 de novembro de 1734 (AHU. Goiás. Doc. 12, 1734), seguida das viagens feitas pelo então governador D. Luís de Mascarenhas ao norte da Capitania de Goiás, em 1740, (AHU. Goiás. Doc. 139, 1741). Na época, Mascarenhas regularizou os últimos achados auríferos, fundando os arraiais de Natividade, Conceição, Cavalcante e Arraias.

Mascarenhas também organizou outras expedições com destino às regiões de Terras Novas, Ribeira da Palma, Pernatinga e Ribeira do Paranã, todas chefiadas pelo coronel 
José Veloso Barreto do Rego e, por fim, a de maio de 1741, quando seus homens percorreram todo o espaço compreendido entre os rios Manoel Alves Grande e Pequeno, as cabeceiras do Paranaíba e do Urussuí e o rio das Balsas até as raias do Gilbuez. Com base nesses dados, pode-se inferir a concomitância de inúmeras ações de Portugal, como os mapeamentos do território e as viagens por diversas direções, as quais visavam atender às questões econômicas e também alcançar um território fundamental para a articulação do litoral com o interior da colônia, o que garantiria sua posterior ocupação.

Antes do início das jornadas de D. Luís de Mascarenhas e dois anos após a chegada dos padres matemáticos (1736), a criação da capitania e a fundação de Vila Boa já faziam parte dessas iniciativas para a legitimação dos territórios avançados. As decisões de ordem administrativa e jurídica, somadas à representação de caminhos que articulavam os territórios apresentados no mapa de 1746, e as frequentes movimentações exploratórias nos territórios centrais do Brasil revelam a importância de Goiás e Mato Grosso no âmbito das discussões que antecederam as negociações entre Portugal e Espanha sobre os limites de terras. As duas capitanias foram essenciais para a interligação dos diferentes espaços da colônia.

Outras fontes cartográficas e ações administrativas inserem Goiás mais enfaticamente nesse contexto de discussão e posse do território, anteriormente à assinatura do Tratado de Madri. Supõe-se que, mesmo não tendo sido tais fontes utilizadas na execução do referido mapa de 1746 , certamente eram do conhecimento do governador Gomes Freire de Andrade, que estava sobejamente interessado no mapeamento das terras conquistadas. É o caso, por exemplo, da carta (1744) sobre a jurisdição eclesiástica das Terras Novas - norte de Goiás -, pertencentes ao bispado do Grão-Pará (Doc. In: MATOSO, 1999). Complementam este conjunto de documentos os estudos feito sob o incentivo de Alexandre de Gusmão (abril de 1745), para a criação dos bispados de São Paulo, Mariana (Minas Gerais) e para as prelazias de Cuiabá e Goiás, bem como uma Resolução da Corte, de 7 de maio de 1748, que apresenta os limites destes territórios eclesiásticos, exceto os de Cuiabá (AHU. Goiás. Doc. 2360, 1790).

Além dos interesses relacionados à obtenção de informações sobre as regiões mais centrais da colônia, Freire de Andrade, ao chegar a Goiás em 1749, tomou conhecimento também da zona diamantífera dos rios Claro e Pilões, declarando a demarcação e a proibição 
de se minerar nessas terras (AHU. Goiás. Doc. 749, 1715). Mas a necessidade de conhecer melhor essa região, somada às dificuldades de governar uma grande extensão territorial que cobria desde o Rio de Janeiro até o sul da comarca de São Paulo e daí até o rio da Prata, fez com que o governo colonial separasse as Capitanias de Goiás e Mato Grosso (BERTRAN, 1997).

Para o governo do Mato Grosso foi nomeado D. Antônio Rolim de Moura e, para Goiás, vindo de Pernambuco, D. Marcos de Noronha, que trouxe uma instrução do Estado, de 19 de janeiro de 1749, para estabelecer as linhas de fronteira do território sob governo (AHU. Goiás. Doc. 500, 1752). Para auxiliá-lo, o secretário de Estado Marco Antônio de Azevedo Coutinho determinou-lhe que se recolhesse notícias com Gomes Freire para a formação dos limites da capitania (AHU. Goiás. Doc. 500, 1752).

O novo governador chegou a Vila Boa de Goiás em 8 de novembro de 1749 e deu início ao seu trabalho com o inquérito geográfico e etnográfico do local, encomendando ao engenheiro Tosi Colombina o exame dos diversos arraiais para obtenção dos graus em que ficavam das distâncias em que se encontravam em relação um ao outro (AHU. Goiás. Doc. 457, Anexo de 16-08-1750). Além disso, solicitava um cuidadoso levantamento das nações indígenas, situando-as em relação aos diversos rios e ainda identificando os costumes dos gentios (AHU. Goiás. Doc. 457, Anexo de 16-08-1750). Todas essas providências certamente fizeram parte de uma pesquisa maior, determinada anteriormente por Gusmão quando se dirigiu a um funcionário lisboeta para "[...] traçar uma carta das regiões percorridas com as latitudes (altura em graus) e longitudes (distâncias a um ponto fixo) respectivas; e o âmbito invulgar da pesquisa etnográfica, que abrange o governo, trajes, costumes e religião dos povos indígenas e sua história" (CORTESÃO, 1965, p. 152). Em Goiás, esse trabalho pode estar vinculado à execução de um mapa sobre sua situação territorial antes mesmo da chegada do cartógrafo Tosi Colombina. O referido mapa foi encaminhado por Ângelo dos Santos Cardozo a Alexandre de Gusmão em 12 de maio de 1750, e nele estavam registrados os arraiais goianos, o caminho que vem da Vila de Santos para Vila Boa e daí para Cuiabá e Rio Madeira. (AHU. Goiás. Doc. 740, 1755).

Mas as obrigações de D. Marcos não paravam por aí. Imediatamente após sua chegada, uma provisão lhe ordenava fazer um parecer com o qual se pudesse determinar a divisão da Capitania de Goiás. Naquele momento, a ideia de um território desenhado já 
estava formada, pois, dois meses após sua chegada, em 12 de janeiro de 1750, e dois dias antes da assinatura do Tratado de Madri, sua proposta já se encontrava em tramitação com a indicação das balizas naturais com seus respectivos nomes e localizações. Para dar início às atividades, D. Marcos tomou como referência Vila Boa de Goiás e a Vila do Bom Jesus, capital de Cuiabá, calculando entre elas uma diferença de "[...] cinco graus de distancia, medidos pello rumo do Noroeste, e Sueste, ficando a ditta Villa Boa a Sueste, e a Villa do Bom Jezus ao Noroeste" (AHU. Goiás. Doc. 740, 1755). Em seguida, verificou a posição central da distância entre as duas vilas e destas para o rio das Mortes, esclarecendo não ser este o mesmo que existe em Minas Gerais.

Ao longo do rio das Mortes ficaria a linha de divisão entre a Capitania de Goiás e a Capitania do Mato Grosso (AHU. Goiás. Doc. 429, 1750). Pelo leste, o território de Goiás faria divisa, como já havia sido decidido anteriormente, com São Paulo e Minas Gerais, porém, para esta última capitania, apontava os equívocos referentes à descoberta de Paracatu, localizado próximo à serra do Lourenço Castanho. Para D. Marcos de Noronha, esta região, anteriormente pertencente a São Paulo, por direito deveria ser de Goiás. No entanto, D. João V havia se decidido por Minas Gerais, ficando a capitania goiana "[...] devidida das geraes pella devizão antecedente, pella parte de Leste, e da de São Paulo pella parte Sul, pello Rio Grande o geral, que corre do Norte para o Sul, e vay dezaguar no Paraguay" (AHU. Goiás. Doc. 429, 1750). Estabelecidas essas linhas, restavam apenas as indicações de fronteiras com o Norte, com as capitanias de Maranhão e Pará. Todavia, o governador não obteve informações precisas sobre a geografia do local, desconhecendo, portanto, a existência de serras e rios que pudessem servir como divisas. Por isso, propôs ser "[...] devidida esta Capitania da do Maranhão, e da do Grão Pará pella devizão que antecedentemente tinha o Governo de S. Paulo, com o Governo do Maranhão, e Grão Pará [...]" (AHU. Goiás. Doc. 429, 1750).

A generalidade do mapa descritivo de D. Marcos de Noronha, que trazia apenas a indicação dos locais que poderiam ser as balizas naturais de Goiás, e a urgência do trabalho para o rápido encaminhamento de dados à Corte portuguesa induziram o governador a solicitar ao engenheiro italiano Tosi Colombina, a elaboração de um novo mapa. Para tanto, ele se decidiu pelo aproveitamento de informações anteriores, como a cópia de um outro mapa que já havia sido enviado por Ângelo dos Santos Cardozo a Gusmão, mapas de 
sertanejos e, possivelmente, as indicações feitas para os limites da prelazia (AHU. Goiás. Doc. 740, 1755). A correção desse novo mapa se fez ainda pela observação de alguns lugares, tal qual a indicação dos métodos práticos apresentados pelo já citado Tratado de 1722, de Manuel de Azevedo Fortes, que utilizava instrumentos mais comuns, como a bússola. Somente com esses procedimentos se podia calcular com mais precisão as braças, os graus e as distâncias de um território. Na medida do possível, esse deve ter sido o método utilizado por Tosi Colombina para a elaboração do referido mapa geral e de outro, cuja autoria é atribuída a ele, no qual aparecem representados os arraiais goianos (Figuras. 1 e 2).

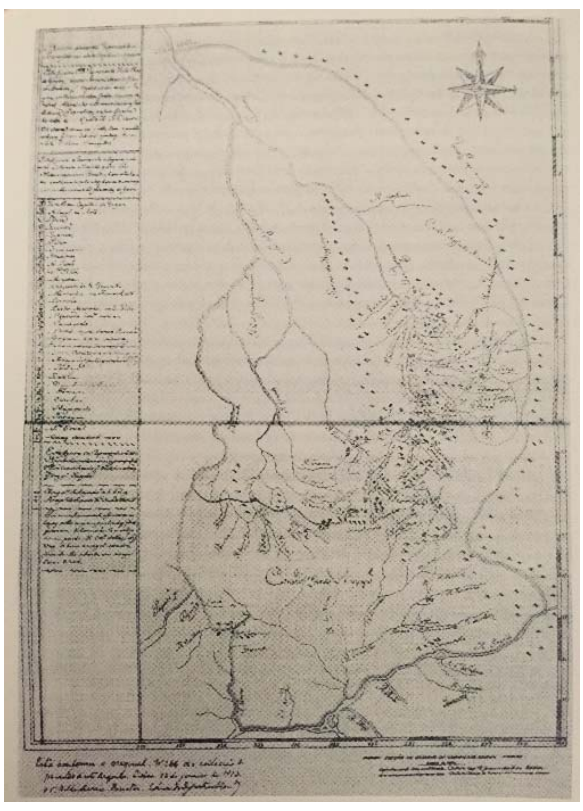

Fig. 1 - Mapa atribuído a Tosi Colombina, 1751. Fonte: IPEHBC

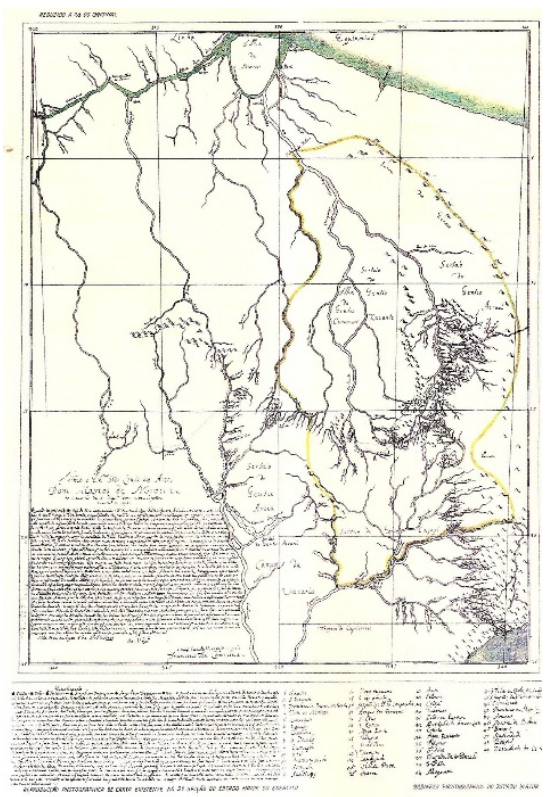

Fig. 2 - Mapa de Tosi Colombina, séc. XVIII. Fonte: IPEHBC

Acompanhado do ouvidor na Correição da Comarca, Tosi Colombina iniciou a confecção do mapa de Goiás em 1750, a partir da busca das informações que lhe pareceram mais confiáveis. Em 6 de abril de 1751, com o trabalho já concluído, o engenheiro encaminhou o mapa a D. Marcos de Noronha, anexo a uma carta na qual diz ter alcançado uma visão mais exata desse sertão incógnito. Afirmava, ainda, que quem melhor havia se aproximado da verdade fora o Padre Capacci, mas com a ressalva de que o levantamento do jesuíta estava incompleto, pois ele não havia ultrapassado o distrito do Tocantins.

Esse mapa foi um dos resultados do avanço do conhecimento no século XVIII, que ocorreu com a evolução da antiga ciência e da arte náutica dos cosmógrafos da fase do descobrimento para a das escolas de engenharia. Surgiram, então, os importantes tratados teórico-práticos da cartografia, elaborados com base em latitudes e longitudes e em 
levantamentos topográficos que buscavam a legitimação das áreas de expansão. Passava-se da dinastia dos Pimentéis para a dos engenheiros-mores, cujo exemplo máximo foi Azevedo Fortes. No Brasil, o momento se caracterizou pela construção de cartas geográficas, abertura de caminhos terrestres e fluviais e construção de fortalezas no interior do território (CORTESÃO, 1965, p. 317). Entre estas, um bom exemplo é o Príncipe da Beira, no Guaporé. Entre os trabalhos cartográficos, destaca-se o de Tosi Colombina, que registrou os caminhos terrestres e fluviais entre São Paulo e Cuiabá e entre o Prata e o Amazonas.

\section{Considerações finais}

A compreensão da urbanização de Goiás no século XVIII requer a consideração de vários condicionantes intrinsecamente relacionados à centralizadora política de colonização portuguesa, voltada particularmente para a expansão, a ocupação e a exploração econômica do território. Mas não foram essas ações mais pragmáticas as únicas responsáveis por esse processo. A ele deve-se acrescentar também a persistência de antigos mitos sobre a existência de ouro e pedras preciosas na região, que motivaram bravos expedicionários a penetrar e a desbravar o mais central de todos os sertões do Brasil.. Só assim, enfrentando o desconhecido, esses homens conseguiram converter o vazio da ignorância sobre esse espaço em território identificável, mensurável e mapeado, mostrando assim outras potencialidades além daquelas almejadas pelo imaginário. Ou seja, à medida que o penetravam, renovavam continuamente suas visões míticas, descobrindo suas jazidas auríferas, seus atributos detratores e a natural resistência de seus habitantes, aperfeiçoando sua forma de representação segundo uma cartografia mais exata e que revelava um conhecimento elaborado, erudito, buscando, sobretudo, garantir o controle e a posse das terras goianas, particularmente daquelas situadas a oeste do meridiano de Tordesilhas.

Tais objetivos não se efetivaram apenas com base nessa cartografia mais precisa e da tradição dos engenheiros militares, mas contaram também com outras estratégias da Coroa, como aquelas adotadas na época da descoberta do ouro nas áreas centrais da colônia brasileira. Foi nesse momento que o governo metropolitano ampliou seu controle e supervisão no sertão com medidas que redefiniram um claro programa de ocupação desse território. Em Goiás, essas novas orientações chegaram logo no início do século XVIII após as notícias das minas do rico metal encontradas por Bartolomeu Bueno da Silva. Tais orientações contribuíram para a definição dos limites territoriais da capitania, para o 
incentivo à busca de novas minas, para a formação de núcleos urbanos, para a instalação da capital Vila Boa, para a instituição da capitania, para a abertura de caminhos reais e postos alfandegários, para os inúmeros levantamentos topográficos e o desenho dos vários mapas feitos por sertanistas e engenheiros militares, como Tosi Colombina. Todos esses mecanismos, apesar de possuírem suas especificidades, funcionavam segundo um sistema que claramente os articulava, constituindo um método de construção e urbanização de territórios que foi comum a todo o Império luso.

\section{REFERÊNCIAS BIBLIOGRÁFICAS}

ARAÚJO, Renata Malcher de. As cidades as Amazônia no século XVIII. Porto/Portugal: FAUP publicações, 1998.

BERTRAN, P. (Org.). Notícia geral da Capitania de Goiás, V1. Goiânia: UFG/UCG/; Brasília: Solo Editores, 1997.

CONCEIÇÃO, M. T. A praça da guerra: aprendizagens entre a Aula do Paço e a Aula de Fortificação. Oceanos, Lisboa, n. 41, p. 24-38, jan./mar. 2000.

CORTESÃO, J. Z. História do Brasil nos velhos mapas. Rio de Janeiro: Ministério das Relações Exteriores - Instituto Rio Branco, 1965. fac-similar.

Alexandre de Gusmão e o Tratado de Madrid, V. 2. Brasília: Senado Federal, 2001. Edição

D’AGOSTINO, M. H. S. João Baptista Lavanha, Vitrúvio e o Renascimento. In: MARQUES, L. (Org.). A constituição da Tradição Clássica. São Paulo: Hedra, 2004. p. 289-311.

DELSON, R. M. Novas Vilas para o Brasil colônia: planejamento espacial e social no século XVIII. Brasília: Alva-Cord, 1997.

FERREIRA, M. C. Uma ideia de Brasil num mapa inédito de 1746. Oceanos n. 43, Lisboa: C.N.C.D.P., p. 184-195, 2000.

. O tratado de Madri e o Brasil Meridional: os trabalhos demarcadores das partidas do Sul e a sua produção cartográfica (1749/1761). Lisboa: C. N. C.D.P., 2001.

Mimeografado.

Cartografia e Diplomacia: o Mapa das Cortes e o Tratado de Madri. Porto, out. 2005.

GUERREIRO, I. Fronteiras do Brasil colonial. A cartografia dos limites na segunda metade do século XVIII. Oceanos, n. 40, Lisboa: C,N.C.D.P. , p. 24-42, 1999.

MATOSO, Caetano da Costa. Códice Costa Matoso. Belo Horizonte: Fundação João Pinheiro, Centros de Estudos Históricos e Culturais, 1999. 
MOREIRA, R.; ARAÚJO, R. M. A engenharia militar do século XVIII e a ocupação da Amazônia. In: MAGALHÃES, J. R. Amazônia Felsínea. Lisboa: C. N. C. D., 2000. p. 173-196.

PALACIN, L. O século do ouro em Goiás: 1722-1822, estrutura e conjuntura numa capitania de Minas. 4. Ed. Goiânia: Editora da UCG, 1994.

REIS MIRANDA, T. C. P. Entradas e fronteiras. In: MAGALHÃES, J. R. (Org.). Brasil, brasis: cousas notáveis e espantosas, a construção do Brasil, 1500-1825. Lisboa: C.N.C.D.P, 2000. p. 31-39.

ROSSA, W. A cidade portuguesa. In: PEREIRA, P. (Org.). História da arte portuguesa. Barcelona: Círculo de Leitores, 1995. v. 3. p. 233-321.

SIQUEIRA BUENO, B. P. Desenho e desígnio: O Brasil dos engenheiros militares (1550-1822). Tese (Doutorado) - Faculdade de Arquitetura e Urbanismo da USP, São Paulo, 2001.

TEIXEIRA, M.; VALLA, M. O urbanismo português. Lisboa: Livros Horizonte, 1999.

DOCUMENTOS

AHSP. Regimento dado a Bartolomeu Bueno da Silva. In: Documentos Interessantes. Capitania de Goiás. v. 32.

AHU. Goiás. Doc. 12, 1734. Goiânia: IPEHBC.

AHU. Goiás. Doc. 139, 1741. Projeto Resgate Barão do Rio Branco. Goiânia: IPEHBC.

AHU. Goiás. Doc. 429, 1750. Goiânia: IPEHBC.

AHU. Goiás. Doc. 457, Anexo de 1750. Projeto Resgate Barão do Rio Branco. Goiânia: IPEHBC.

AHU. Goiás. Doc. 500, 1752. Projeto Resgate Barão do Rio Branco. Goiânia: IPEHBC.

AHU. Goiás. Doc. 740, 1755. Goiânia: IPEHBC.

AHU. Goiás. Doc. 1715, 1749. Anexo. Projeto Resgate Barão do Rio Branco. Goiânia: IPEHBC.

AHU. Goiás. Doc. 2360, 1790. Goiânia: IPEHBC. 